\title{
An Unusual Cause of Cholangitis
}

\author{
Pablo Cortegoso Valdivia ${ }^{a}$ Ludovica Venezia $^{a}$ Stefano Rizza $^{a}$ Luigi Chiusa $^{b}$ \\ Claudio Giovanni De Angelis ${ }^{c}$

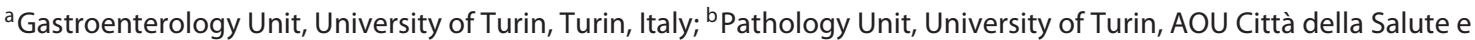 \\ della Scienza, Turin, Italy; ' ${ }^{\circ}$ Gastroenterology Unit, AOU Città della Salute e della Scienza, Turin, Italy
}

\section{Keywords}

Cholangioscopy · Cholestasis · Diagnosis · Endoscopic ultrasonography · Endoscopy · Endosonography · Liver transplantation

\section{Uma causa incomum de colangite}

\section{Palavras chave}

Colangioscopia · Colestase - Diagnóstico - Ecoendoscopia · Transplante hepático

A 57-year-old man with unremarkable previous medical history presented with acute cholangitis and cholestasis. An abdominal computed tomography showed a dilation of the biliary system with hypodense irregular filling defects in the common bile duct (CBD) and previously unknown liver cirrhosis.

The papilla was normal; a subsequent intraductal ultrasonography showed multiple papillary projections in the CBD (Fig. 1). These findings were confirmed by cholangioscopy [1], which identified multiple lesions with "fish-egg" appearance protruding in a dilated CBD filled

\section{KARGER}

E-Mail karger@karger.com www.karger.com/pjg
(C) 2019 Sociedade Portuguesa de Gastrenterologia Published by S. Karger AG, Basel

\section{Karger}

Open access

This article is licensed under the Creative Commons AttributionNonCommercial-NoDerivatives 4.0 International License (CC BYNC-ND) (http://www.karger.com/Services/OpenAccessLicense). Usage and distribution for commercial purposes as well as any distribution of modified material requires written permission. with whitish mucus (Fig. 2). Biopsies with microforceps on the papillary lesions (Fig. 3) were performed, and histological examination highlighted the presence of papillary proliferation with focal high-grade dysplasia without stromal invasion, thus confirming the final diagnosis of intraductal papillary neoplasm BillN-3 (Fig. 4) [2].

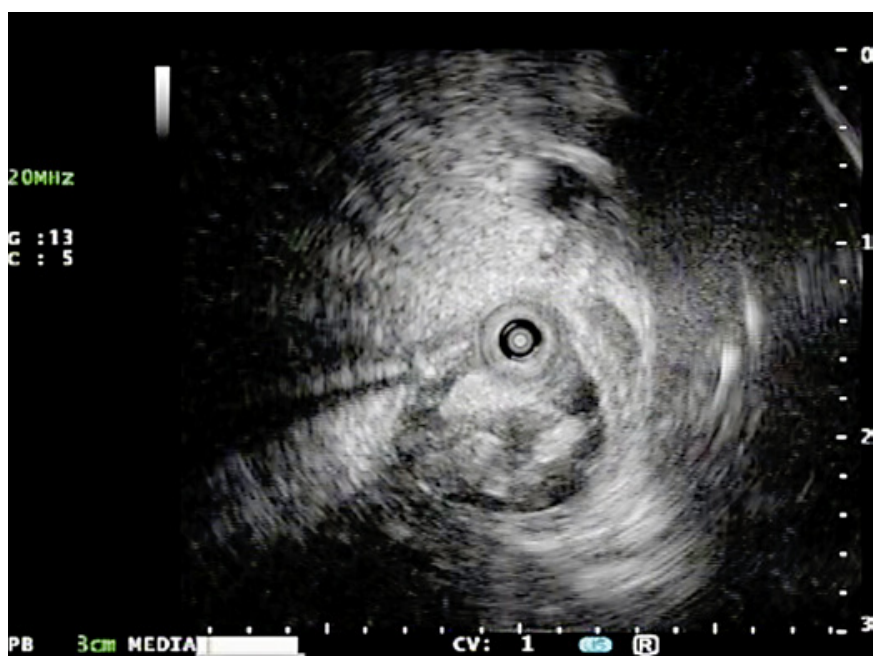

Fig. 1. Intraductal ultrasonography: dilated CBD with papillary projections.
Pablo Cortegoso Valdivia

Gastroenterology Unit, University of Turin Corso Bramante 88-90 IT-10126 Turin (Italy)

E-Mail cortegosopablo@yahoo.it 


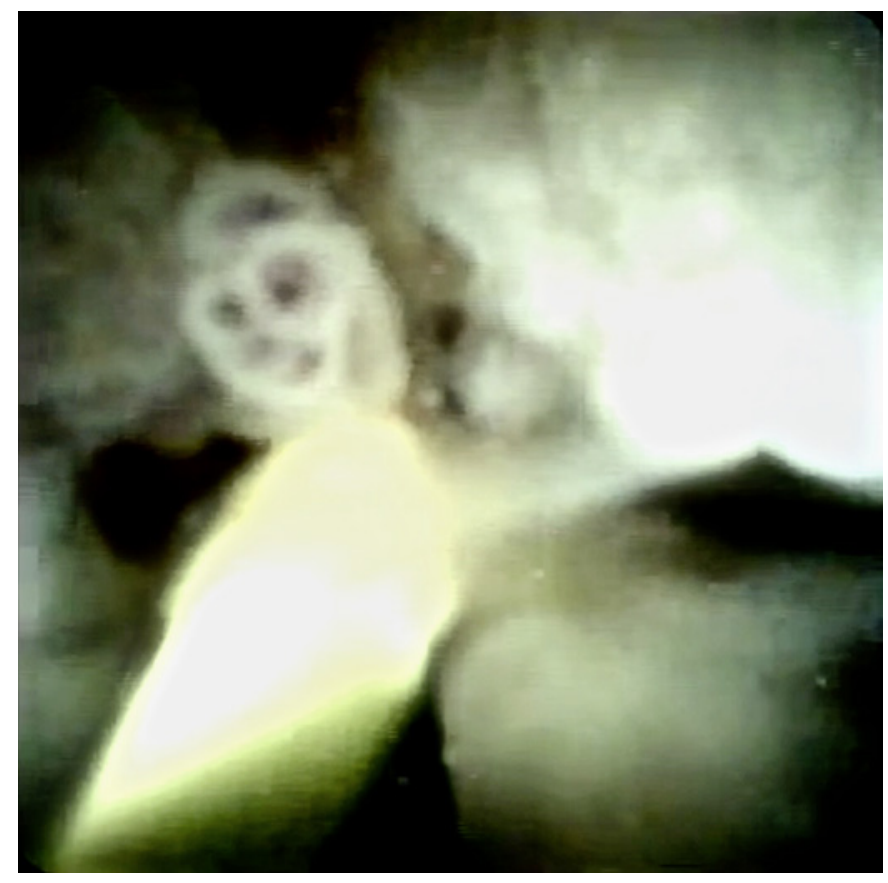

Fig. 2. Cholangioscopy: CBD lesions with "fish egg” appearance.

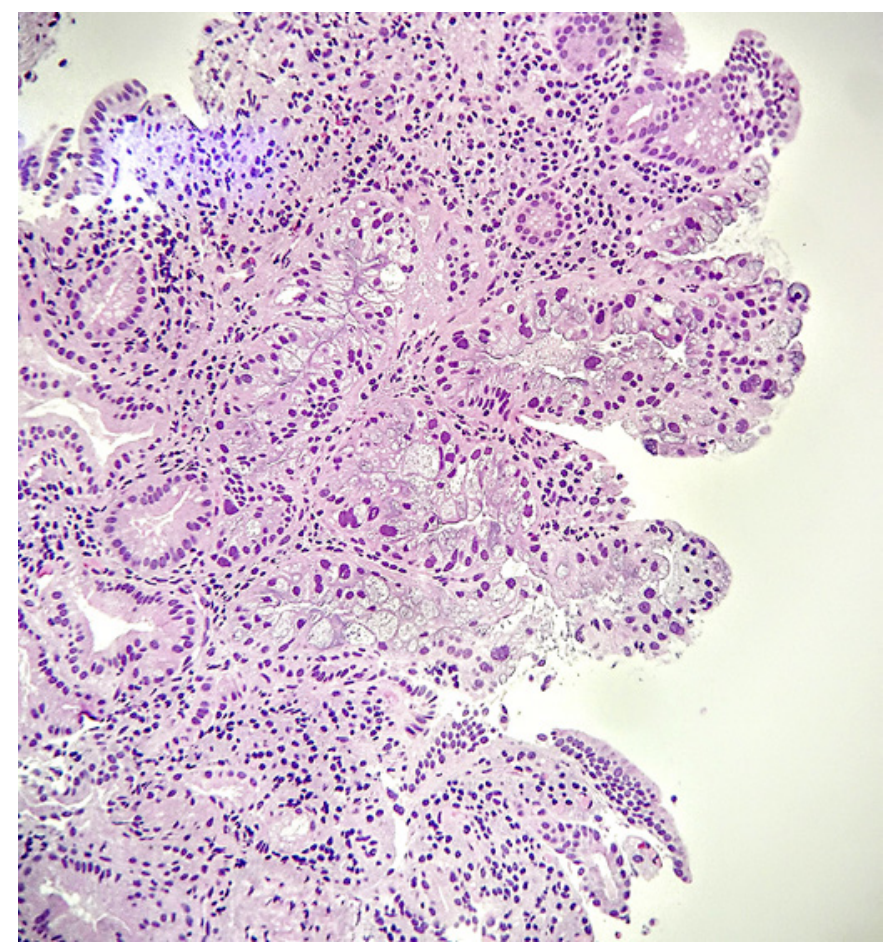

Fig. 4. Papillary proliferations with high-grade dysplasia.

An Unusual Cause of Cholangitis

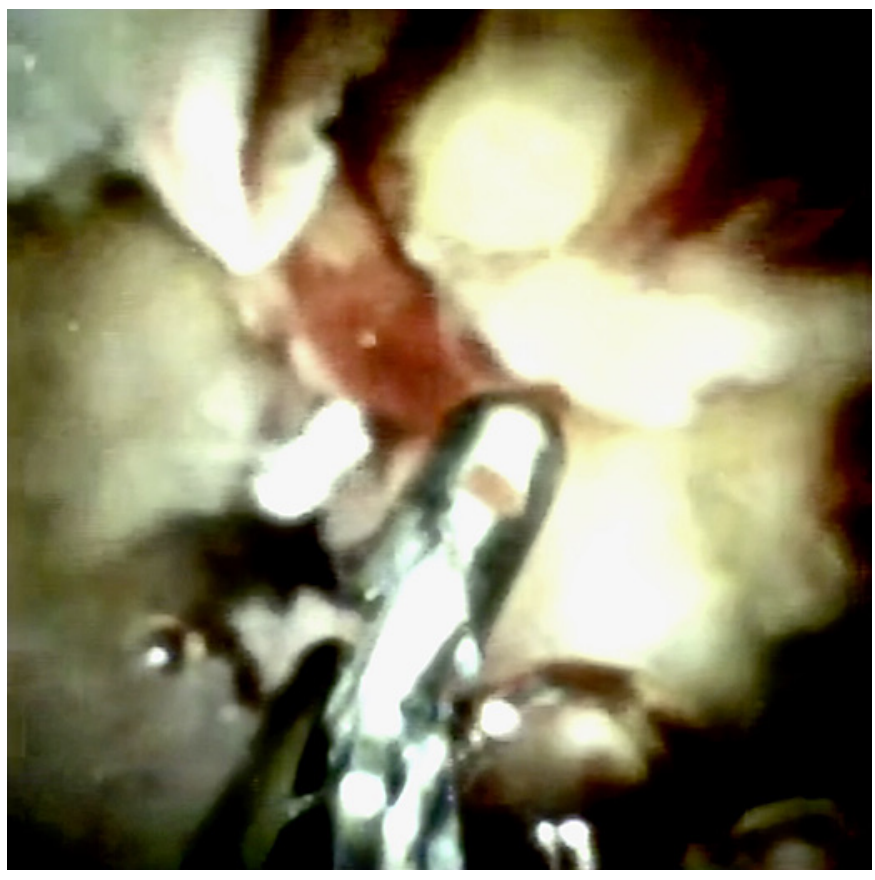

Fig. 3. Cholangioscopy: biopsy with microforceps.

Due to the high rate of malignant transformation of this disease despite its slow progression, after multidisciplinary discussion the patient has now been referred and selected for orthotopic liver transplantation [3].

\section{Statement of Ethics}

This material has not been published in whole or in part elsewhere; the manuscript is not currently being considered for publication in another journal; all authors have been personally and actively involved in substantive work leading to the manuscript and will hold themselves jointly and individually responsible for its content.

\section{Disclosure Statement}

All authors declare that there is no conflict of interest related to this manuscript.

\section{Author Contributions}

P. Cortegoso Valdivia and L. Venezia equally contributed in writing the manuscript, S. Rizza contributed to its editing and selection of the images, L. Chiusa analyzed and provided images of the histological specimens, and C.G. De Angelis contributed with critical revision.

GE Port J Gastroenterol 2020;27:56-58 
References
1 Parsi MA. Biliary papillomatosis: diagnosis with direct peroral cholangioscopy. Gastrointest Endosc. 2015 Jan;81(1):231-2.

2 Wan XS, Xu YY, Qian JY, Yang XB, Wang $\mathrm{AQ}, \mathrm{He} \mathrm{L}$, et al. Intraductal papillary neoplasm of the bile duct. World J Gastroenterol. 2013 Dec;19(46):8595-604.
3 Luvira V, Pugkhem A, Bhudhisawasdi V, Uttaravichien TU, Sripanuskul A, Pongskul J, et al. Papillomatosis of the Biliary Tree and Gallbladder: Successful Treatment With Repeated Resection and Liver Transplant. Exp Clin Transplant. 2017 Dec. doi: 10.6002/ ect.2017.0121. 